$\underline{\text { ICONE15-10026 }}$

\title{
DRAFT
}

\section{Status of the INL Gas Reactor Test System Experiment Facility}

\author{
Theron Marshall \\ Idaho National Laboratory (INL) \\ Idaho Falls, Idaho USA \\ 208.569.7515 \\ theron.marshall@inl.gov
}

\section{John Groome \\ Oregon State University \\ Corvalis, Oregon USA \\ 541.737.7065 \\ john.groome@orst.edu}

\author{
Jose Reyes \\ Oregon State University \\ Corvalis, Oregon USA \\ 541.737 .7065 \\ reyes@ne.orst.edu
}

Charles Tschaggeny

INL

I.F. ID USA

208.276.8826

charles.tschaggeny@inl.gov

\begin{abstract}
The Gas Reactor Test System (GRTS) is an experiment facility for examining the thermal hydraulic performance of the Generation IV, Very High Temperature Reactor (VHTR) during a LargeBreak Loss of Coolant Accident (LB-LOCA). The LB-LOCA is defined as the double guillotine break of the VHTR coaxial inlet and outlet cross duct. Two system safety codes, MELCOR and RELAP5-3D were used to calculate core temperatures and flow rates during the LB-LOCA transient. Computational fluid dynamics modeling of the transient produced flow vectors and gas species distribution. The most important phenomenon during the transient is the lock-exchange process, which suppresses the onset of natural circulation until considerable molecular diffusion has occurred. The GRTS was designed based upon a hierarchical two tier scaling analysis whose primary objective was replicating the lockexchange and natural circulation characteristics of the VHTR. The GRTS uses a scaled graphite core to represent the VHTR's graphite core. An in-depth scaling analysis was performed for the GRTS in order to ensure that it accurately simulated the VHTR thermal responses. RELAP5-3D thermal analyses, ProEngineer stress analyses, and combined FLUENT - STARCD CFD analyses have provided a system design that fulfills the GRTS mission statement. This paper discusses the design analyses and their implications on the GRTS capabilities. A discussion is also presented on the preliminary instrumentation plan. The GRTS will provide an extensive temperature map of the VHTR core outlet plenum and its core support, oxygen transport rates
\end{abstract}

during the lock-exchange phenomenon, and thermal conduction rates from the core to the vessel. As a result of the GRTS using helium coolant at $950 \mathrm{C}$, the resulting experiment data is expected to considerably extend the U.S. database for hightemperature gas reactor operations. Finally, the discussion will present conclusions from the GRTS manufacturing and quality control processes that may benefit the VHTR design.

\section{Introduction}

A high-temperature, helium-cooled thermal reactor is currently being proposed for power generation in the United States (U.S.) and abroad. In the U.S., the reactor concept has been termed the Very High Temperature Reactor (VHTR). While there are advances in fuel technology that will result from the commercialization of such a reactor concept, the primary asset that the reactor concept proffers is its high-temperature process heat. This process heat, available from core outlet temperature of $1000 \mathrm{C}$, would enable such applications as hydrogen production, process heat for the petrochemical industry, or other chemical process industries.

The VHTR design studies have leveraged the experience of gas-cooled reactors in the United Kingdom and Germany to satisfy the safety goals of the Generation IV International Forum, an assembly of international nuclear energy experts. Like most graphite-moderated thermal reactors, the VHTR design benefits from the large thermal inertia created by the graphite. Graphite's melting temperature is in 
excess of $3500 \mathrm{C}$, thus a considerable about of heat can be deposited into the graphite core components before their thermal limits are encountered.

While the inclusion of graphite core components unmistakably improves the passive safety rating of the VHTR, there are concerns regarding the "burning" of the graphite during an air ingress transient such as the Loss of Coolant Accident (LOCA). Graphite studies at the Idaho National Laboratory (INL) have provided a range of temperatures that correlate to the oxidation rate of graphite. These studies have also suggested that nuclear grade graphite will not burn, in terms of a flame, for the LOCA transients expected for the VHTR. This analyses and discussions in this paper are based upon the INL graphite studies.

The Large-Break LOCA (LB-LOCA) is a design basis transient that originated with light water reactors. However, there is substantial evidence that nuclear regulatory agencies, e.g., the U.S. Nuclear Regulatory Commission licensing of the Fort Saint Vrain gas-cooled reactor [], will dictate that gascooled reactor similarly demonstrate their ability to prevent off-site releases as a consequence of a LBLOCA. Typically, LOCA analyses for gas-cooled reactors are based upon the experiments performed by Hishida and Takeda in 1991, 1992, and 1996 (Figure 1) [ ]. The system code RELAP5-3D has successfully modeled the Hishida-Takeda experiments (Figure 2) [] and the computational fluid dynamics code FLUENT has also been used to successfully model the experiments []. However, the Hishida-Takeda experiments are a simplification of the air ingress transient in that the experiments do not account for the influence of core pressure drop as a function of core internals, the effects of graphite oxidation, or the stagnation in gas flow caused by the lock-exchange phenomenon. Lastly, the HishidaTakeda data does not allow the analyst to observe oxygen concentrations or the transport of oxygen during the transient.

The INL Gas Reactor Test System (GRTS) was proposed to extend the data set created by the Hishida-Takeda experiments so that LB-LOCA calculations for the VHTR could be validated.

\section{Background}

Analysts at the INL independently performed LBLOCA analyses for the two gas-cooled reactor concepts under the Generation IV umbrella. The first analysis was performed using the system code
MELCOR [] and the pebble bed variant of the VHTR. The second analysis was performed using the system code RELAP5-3D and the Gas-cooled Fast Reactor (GFR) concept. Comparison of the core temperatures and flow rates for the two analyes reveal that the onset of natural circulation was considerably suppressed during the VHTR LBLOCA. Whereas natural circulation was readily initiated following the gas expansion of the LBLOCA in the GFR, natural circulation in the VHTR was not initiated until 200 hours after the LB-LOCA onset in the VHTR (Figure 1).

Careful studies were performed on the MELCOR predictions in order to determined when the delayed natural circulation was an artifact of analyst and/or code error. These studies concluded that the delayed natural circulation was the consequence of the lock-exchange phenomenon.

\section{Theory}

\subsection{Scaling Analysis for Air Ingress Related Phenomena}

This section identifies some of the important mechanisms that cause the ingress of air into the VHTR subsequent to a double-ended break of the hot duct connecting the reactor vessel to the power conversion system. The two phenomena examined in this section are air-ingress via the lock-exchange phenomenon and air-ingress by molecular diffusion. The governing equations for each phenomenon and their respective dimensionless groups and similarity criteria are presented. Lastly, a bounding analysis is performed to obtain a transient solution for the case of molecular diffusion of air into an isothermal helium gas.

\subsubsection{Air Ingress by Lock-Exchange Flow}

A review of the Depressurized Conduction Cooldown scenario reveals that the onset of air ingress into the VHTR following a double-ended break of the hot duct inlet will be initiated by a lock-exchange phenomenon. Figure 4 depicts the expected sequence of events in the VHTR lower plenum following the depressurization of the reactor vessel.

The onset of the phenomena is triggered by the intrusion of a "nose" of cold air that enters at the bottom of the hot duct as shown in the schematic. This creates a counter-current flow in the hot duct. The cold air travels along the bottom of the hot duct forming a cold plume into the lower plenum. Hot 
helium travels along the top of the duct out the break. The cold air entering the lower plenum produces a head wave that travels back and forth along the bottom of the lower plenum creating a wavy interface that further promotes mixing. Eventually the lower plenum fills with cold air to the top of the hot duct creating an interface with the thermally stratified helium. The formation of this relatively quiescent interface serves as the starting point for a long period of molecular diffusion of air into the helium. A similar situation will occur on the cold duct side of the VHTR.

\subsubsection{Air Ingress by Molecular Diffusion}

This section presents an analysis of the air-ingress phenomenon that arises subsequent to the initial period of lock-exchange mixing that occurs following depressurization of the reactor vessel. The end state of the lock-exchange mixing process is the establishment of an air-helium interface at the bottom of the core. The higher temperature helium resides above the lower temperature air. Over a prolonged period, air will slowly diffuse into the helium. Similarly, helium will diffuse into the air. It is proposed that the helium-air mixture, being lighter than air alone, will travel along the top of the hot duct out into the environment via counter-current flow as shown in Figure 5. Similar behavior occurs in the cold gas annular region. It is likely that this phenomenon will occur in a cyclic manner of concentration build-up and subsequent release.

The following assumptions have been made in this analysis:

1. The flow was one-dimensional along the loop axis, therefore fluid properties were uniform at every cross-section.

2. The Boussinesq approximation was applicable.

3. The fluid was incompressible. (Mach number $<0.3$ )

4. The cold side and hot side temperatures were constant.

5. The diffusion coefficients are independent of gas concentration.

6. The molar average velocity, w, can be used in the momentum equation (Hishida and Takeda, 1991)

In their experimental studies of air-ingress, Hishida and Takeda calculated gas mixture velocities between $10^{-6}$ to $10^{-3} \mathrm{~m} / \mathrm{s}$ at the onset of natural circulation. Their comparisons to the data using this approach were quite successful.

\subsubsection{Scale Ratios for Air Ingress Phenomena}

The similarity criteria for the air ingress phenomena were obtained by setting the model to prototype ratio of each dimensionless group to unity. The equations were then solved to obtain the following scale ratios for the air-ingress phenomena.

Lower Plenum Velocity/Hot Duct Diameter Ratio:

$$
\left(u_{L P}\right)_{R}=\left(\frac{d \Delta \rho}{\rho_{C}}\right)_{R}^{1 / 2}
$$

Diffusion Time Scale Ratio:

$$
\left(\tau_{H}\right)_{R}=\left(\frac{L_{o}^{2}}{D_{H}}\right)_{R}
$$

Diffusion Coefficient Ratio:

$$
\left(\frac{D_{C}}{D_{H}}\right)_{R}=1
$$

Geometric/Kinematic Similarity Ratio:

$$
\left[\sum_{i=1}^{N}\left(\frac{l_{i} a_{B}}{L_{o} a_{i}}\right)\right]_{R}=1
$$

Grashoff Number Ratio:

$$
\left(\Pi_{G r}\right)_{R}=\left(\frac{\xi g\left(X_{H}-X_{C}\right)_{o} L_{o}^{3}}{D_{H}^{2}}\right)_{R}
$$

Loop Resistance Ratio:

$$
\left(\Pi_{F}\right)_{R}=\left\{\sum_{i=1}^{N}\left[\frac{1}{2}\left(\frac{f l}{d_{h}}+K\right)_{i}\left(\frac{a_{B}}{a_{i}}\right)^{2}\right]\right\}_{R}
$$

These equations will be solved in conjunction with dimensionless equations to obtain the design parameters and operating conditions for the GRTS.

\subsection{Top-Down Scaling Analysis for Single-}

Phase Natural Circulation

The natural circulation phase of the transient begins when air ingress is sufficient to start natural circulation flow upward through the core. Upward core flow is opposite the normal forced flow direction. Cool air at temperature $\mathrm{T}_{\mathrm{C}}$, enters the broken hot duct pipe, flows into the lower plenum and up through the core where it is heated to a temperature $\mathrm{T}_{\mathrm{H} 1}$. The gas may undergo significant expansion in the core region due to local heating. 
The hot air continues upward through the upper plenum shroud into the upper head where thermal radiation heat transfer from the vessel head cools the hot air to some intermediate temperature. The cooler air then flows downward through the annulus between the core shroud and the reactor vessel. Additional heat removal occurs in the annulus as a result of vessel wall radiation heat transfer. The heated air then vents through the hot duct (normally the inlet path) at an air temperature, $\mathrm{T}_{\mathrm{H} 2}$. A simple sketch of the natural circulation flow path under consideration is presented in Figure 6.

\subsection{Scale Ratios for a Single-Phase Fluid Natural Circulation Loop}

The set of similarity criteria for a single-phase fluid natural circulation loop is obtained by setting the model to prototype ratio of each dimensionless group to unity. Expressions for the time, length, and velocity scale ratios are obtained using the ratio of the characteristic time constant and the steady state solution for the fluid velocity at the core inlet. The following equations present the scale ratios for single-phase natural circulation.

Time Scale Ratio:

$$
\tau_{\text {loop }, R}=\left(\frac{\rho C_{p}}{\beta}\right)_{R}^{1} / 3\left(\frac{a_{c} \Pi_{F} l^{2}}{\dot{q}_{c o}}\right)_{R}^{1 / 3}
$$

Fluid Velocity Scale Ratio:

$$
u_{R}=\left(\frac{\beta}{\rho C_{p}}\right)_{R}^{1 / 3}\left(\frac{\dot{q}_{c o} l}{a_{c} \Pi_{F}}\right)_{R}^{1 / 3}
$$

Temperature Rise Ratio:

$$
\Delta T_{R}=\left(\frac{\dot{q}_{c o}}{\rho_{c} u_{c} a_{c} C_{P}}\right)_{R}
$$

Loop Length Scale Ratio:

$$
l_{R}=\left(L_{t h}\right)_{R}
$$

Flow Area Scale Ratio (Kinematic Similarity):

$$
\left(\frac{a_{i}}{a_{c}}\right)_{R}=1
$$

Loop Energy Scale Ratio:

$$
\left[\frac{\left(T_{H 1}-T_{C}\right)_{o}}{\left(T_{M}-T_{C}\right)_{o}}\right]_{R}=1
$$

Stored Energy Scale Ratio:

$$
\left(\frac{\dot{q}_{\text {Str }, o}}{\dot{q}_{c o}}\right)_{R}=1
$$

Heat Loss Scale Ratio:

$$
\left(\frac{\dot{q}_{\text {loss }, o}}{\dot{q}_{c o}}\right)_{R}=1
$$

\subsection{Scaling Ratios for a $1 / 4$ Scale GRTS}

The previous sections have yielded a set of similarity criteria that can be used to determine the dimensions and operating conditions of a reduced-scale GRTS. Because these similarity criteria are expressed in terms of ratios of model to prototype fluid properties, material properties and geometrical properties, the analyst must make some choices to achieve closure in the design process. That is, substituting these choices into the scaling criteria yields all of the scale ratios needed for the design of the GRTS. This section presents those choices and the rationale used to make these choices.

\subsubsection{Scaling Choices}

Three requirements have been imposed on this analysis. They are fluid property similitude, kinematic similarity, and friction and form loss similarity. To preserve kinematic similarity, it is required that:

$$
\left(\frac{a_{i}}{a_{c}}\right)_{R}=1
$$

Preserving the friction and form loss similarity requires:

$$
\left(\Pi_{F}\right)_{R}=1
$$

In addition, the following scaling ratios have been selected:

Elevation and Length Scaling Ratio

$$
(L)_{R}=1: 4
$$

Diameter Scaling Ratio 
$(D)_{R}=1: 7.54$

\subsubsection{Selection of the Working Fluid}

The working fluid selected for use in the GRTS is helium. The reasons for this selection are as follows:

1. Because helium is the working fluid in the VHTR, fluid property similitude is achieved whenever system pressures are matched. For the low pressure DCC events, this is the duration of the transient. Fluid property similitude greatly simplifies the scale ratios.

2. It has been determined that the flow stability in the core is greatly affected by the gas density. Heavier gases exhibit flow instability behavior under downflow conditions that would not be prototypic of a helium gas system.

3. Helium is readily available and a relatively economic choice of working fluid.

\subsubsection{Selection of the Component Materials}

Stainless steel 304 and Inconel 625 are being considered for the vessel materials. These materials are available commercially and can operate at the temperatures required for DCC transient and low pressure PCC scenarios. The composition of the VHTR vessel materials has not yet been determined.

\subsubsection{Selection of the Operating Pressure}

The primary function of the GRTS will be to examine postulated DCC scenarios. Nonetheless, the GRTS is capable of limited studies up to 9 bar. This decision is based on economics and safety limits for high temperature pressure vessels.

\subsubsection{Selection of the Length and Diameter Scale}

The length scale ratio of the GRTS is 1:4. This length ratio would be applied to all the piping lengths and component elevations, except in specific components where other more important criteria take precedence.

For natural circulation processes (gravity dominated), the time scale corresponding with the $1: 4$ elevation scale requirement is $1: 2$. Therefore to preserve event sequences, all of the transport processes should be scaled to 1:2. The apparent exception is the time scale for air ingress by molecular diffusion which will occur at 1:16 time scale. In this instance, this is desirable because the air-ingress portion of a DCC transient in the full scale VHTR may take upwards of 200 hours.

The diameter scaling ratio for all components has been selected to be 1:7.54. The reason for this selection is as follows:

1. Using these length and diameter scaling ratios, the fluid volume requirements are not excessive.

2. Core power requirements associated with this fluid volume are also reasonable. For example, $300 \mathrm{~kW}$ represents $\sim 5.6 \%$ decay power well within laboratory capability.

3. The time scaling ratio makes the duration of a DCC test reasonable.

4. The component length to diameter ratio $(\mathrm{L} / \mathrm{d})$ indicates that multi-dimensional flow effects will scale well when fluid property similitude exists. $(\mathrm{L} / \mathrm{d}=1.89)$.

5. The diameter ratio assures that skin friction effects in the up-flow annular region do not result in excessive, nontypical, pressure drops that would distort flow behavior and that could not be adjusted.

6. The length and diameter scale ratio requirements can be easily met with commercially available pipe and drawn tubing.

7. Construction and material costs are reasonable for the geometric scales that have been chosen.

\subsubsection{GRTS Scale Ratios}

The cross sectional area and the volume scaling ratio are obtained directly from the scaling choices. That is,

$$
\begin{aligned}
& \left(a_{c}\right)_{R}=D_{R}^{2}=1: 56.85 \\
& (V)_{R}=(a L)_{R}=1: 227.4
\end{aligned}
$$

The core power scale ratio is:

$$
\left(\dot{q}_{c o}\right)_{R}=(a)_{R} L_{R}^{1 / 2}=1: 113.7
$$


The time scale ratio is:

$$
(\tau)_{R}=\left(\frac{a L^{2}}{\dot{q}_{c o}}\right)_{R}^{1 / 3}=1: 2
$$

The velocity scale ratio is:

$$
(u)_{R}=\left(\frac{L}{\tau}\right)_{R}=1: 2
$$

The velocity scale ratio is:

$$
\left(a_{B r k}\right)_{R}=\left(\frac{V_{o}}{t}\right)_{R}=1: 113.7
$$

The lower plenum velocity ratio during air ingress by lock exchange is:

$$
\left(u_{L P}\right)_{R}=(d)_{R}^{1 / 2}=1: 2
$$

The time scale for air-ingress by molecular diffusion is:

$$
\left(\tau_{H}\right)_{R}=\left(L_{o}^{2}\right)_{R}=1: 16
$$

The core pressure drop scaling ratio is:

$$
\left[\Delta P_{\text {Core }}\right]_{R}=\left[L_{\text {th }}\right]_{R}=1: 4
$$

The scaling ratio for the active surface heat transfer area of the GRTS vessel is:

$$
\left(A_{R A D}\right)_{R}=\left(\dot{q}_{c o}\right)_{R}=1: 113.7
$$

The scaling ratio for the thermal resistance in the vessel is:

$$
\left(\sum R_{t h}\right)_{R}=\frac{1}{\left(\dot{q}_{c o}\right)_{R}}=113.7
$$

The scaling ratio for the stored energy release in the core components is:

$$
\left(\rho_{S} C_{P S}\right)_{R}=\frac{\left(\dot{q}_{c o}\right)_{R} t_{R}}{V_{R}}=1
$$

Table 1 summarizes the scale ratios obtained for the GRTS.

\subsection{Preliminary Mechanical Design of GRTS \\ 4.0.1 Core Geometry}

The GRTS inner core section has an outside diameter of $102 \mathrm{~cm}$ and is approximately $229 \mathrm{~cm}$ in height. The figures below show the hexagon geometry of the heat and coolant passages, the bypass channels, and a cutaway view of the core internals contained in the two vessels.

\subsubsection{Computer Assisted Drawings}

A 3-D computer model of the GRTS was created in Pro/Engineer Wildfire 2.0. This model was created to develop the form, fit and function of each of the parts that will make up the GRTS. This model was used to create the rapid prototype model of the core section and the finite element models.

The model consisted of three sub-assemblies. The sub-assemblies are the following:

- Inner vessel - includes the core, the upper and lower plenum shrouds

- Outer vessel - includes the outer pressure vessel

- Base assembly - includes the base and the man access

These assemblies assemble together with the inner and outer vessels are supported by the base assembly and the outer vessel encapsulates that inner vessel.

The overall dimension of the GRTS is $572 \mathrm{~cm}$ tall, $163 \mathrm{~cm}$ in diameter. The core has been model with 9 disks stacked on top of each. Each disk is $23 \mathrm{~cm}$ tall and $102 \mathrm{~cm}$ in diameter. The overall length of the core is $206 \mathrm{~cm}$. There is a gap of $8 \mathrm{~cm}$ between the inner and the outer vessels. To fasten the GRTS together, flanges and capture features have been incorporated in to the design of the GRTS.

Figure 8 shows the exterior of the GRTS which includes the Outer Vessel and the Base Assembly

Figure 9 shows the interior of the GRTS which is referred to as the Inner Assembly. 
Figure 10 shows the Outer Vessel Assembly.

Figure 11 shows the Base assembly. This view has been rotated 180 degrees from other views in order to shown the man access port.

Figure 12 shows an exploded view of the stacks of disks that would make up the core. The exploded view was shown to help to show that 9 separate disks would be stacked on top of each other to make up the core section.

Figure 13 shows an exploded view of the entire GRTS. This view was shown to illustrate how the assemblies and individual components fit together.

\subsection{Finite Element Analysis}

The core section was modeled as one continuous piece and quarter symmetry was employed. The model used for the finite element analysis is shown in Figure 14. The finite element analysis was carried out in two parts. The first part consisted of a thermal analysis of the core which resulted in a temperature profile. The second part consisted of a static analysis in which the calculated temperature profile was used as a thermal load. The core is composed of GBC Cerasil U223 ceramic.

\subsubsection{MESH:}

The finite element analysis was carried out in Pro/Mechanica Wildfire 2.0. The finite element mesh was created using Pro/Mechanica's mesh generator with the following settings: (1) Maximum and minimum allowable angles of 175 and 5 degrees, (2) Maximum allowable aspect ratio of 30 degrees, and (3) Maximum allowable edge turn of 95 degrees.

The following assumptions were used in the creation of the finite element model: Materials linear and elastic, Symmetry may be used, Bottom surface constrained in the axial direction, Worst case loading condition, in which the temperature of the helium is at ambient temperature, Steady-state condition present, CTE constant, the heating of the coolant could be approximated as a logarithm function.

For the heating channels a boundary condition of $1000 \mathrm{C}$ was applied on each heating channel. For the cooling channels a logarithm function was applied on each channel. The logarithm function is given in equation 30. This logarithm function was applied to approximate the heating of the helium as it travels through the cooling channel. The entrance temperature of the helium was assumed to be ambient temperature $(21 \mathrm{C})$ and the exit temperature of the helium was assumed to be the temperature of the heating channel $(1000 \mathrm{C})$.

$$
T=392.58 \times \ln (1+z)+T_{a m b}
$$

Where: $\mathrm{z}$ is the axial distance from the top surface

$$
\mathrm{T}_{\mathrm{amb}} \text { is the ambient temperature/inlet }
$$

temperature of the coolant entering the core

$\mathrm{T}$ is the resultant temperature

\section{THERMAL LOADS}

No thermal loads were applied to the model.

\section{THERMAL ANALYSIS RESULTS:}

The model was run using the single-pass adaptive method to determine when the model had converged. The following pictures shows the resulting temperature profile inside the core as a result of the temperature profiles:

Figure 15 shows how the temperature profile varies in the axial direction of the core.

Figure 16 shows the temperature profile at the top surface of the core section.

Figure 17 shows the temperature profile at the bottom surface of the core section.

Figure 16 shows the resultant temperature profile at the top surface of the core section. The top surface had the largest temperature gradients. Figure 17 shows the resultant temperature profile at the bottom surface. The bottom surface was at a uniform temperature (e.g. no temperature gradient).

\section{Stress - Static Analysis}

The largest temperature gradients, as seen in the thermal analysis were at the top of the core. Since the largest temperature gradient was at the top surface of the core, the static analysis was carried out as a plane 2-D analysis of the top surface.

The finite element analysis was carried out in Pro/Mechanica Wildfire 2.0. The finite element mesh was created using Pro/Mechanica's mesh generator with the following settings: (1) Maximum and minimum allowable angles of 175 and 5 degrees, (2) Maximum allowable aspect ratio of 30 degrees, (3) maximum allowable edge turn of 95 degrees.

The assumptions used in the creation of the finite 
element model are the following: Materials linear and elastic, Symmetry may be used, and Plane analysis.

Symmetric boundary conditions were applied in the appropriate surfaces. The top of the core was constrained in the axial direction only.

Temperature loads were applied to the model. The temperature loads were the results of the thermal analysis.

The model was run using the single-pass adaptive method to determine when the model had converged. The resultant stresses given in principle stresses, are given in the following table and figures.

The following figures show principle stress profiles: Figure 18 shows the first principle stresses. Figure 19 shows the second principle stresses. Figure 20 shows the third principle stresses.

Since the core was a ceramic, maximum normal stress fracture criterion was used as a failure criterion. This approach has great success in predicting the fracture of brittle materiali ${ }^{i}$ The maximum normal stress fracture criterion for compression is given in equation. The maximum normal stress fracture criterion for tension is given in equation .

$$
\begin{gathered}
\sigma_{\text {compressive }}=\operatorname{MAX}\left(-\sigma_{1},-\sigma_{2},-\sigma_{3}\right) \\
\sigma_{\text {Tensile }}=\operatorname{MAX}\left(\sigma_{1}, \sigma_{2}, \sigma_{3}\right)
\end{gathered}
$$

The notation MAX indicates that the largest of the values separated by the comas is to be chosen. The compressive stress is 94310 psi which exceeds the ultimate compressive strength of $87000 \mathrm{psi}$. The tensile stress is 120600 which exceeds the ultimate tensile strength of 10000 psi. When a material exceeds the compressive or the tensile strength of the material, the material has failed and will not be able to withstand the applied loading.

5. Instrumentation

\subsection{Oxygen Sensors}

Figures 21 and 22.

\subsection{Core Power System}

Multi-cell heater cartridges, three axial power zones, three radial power zones. Figure 23 and 24.

\subsection{LB-LOCA System}

LB-LOCA initiation system. Figure 25.

6.0 Results and Current Activities

7.0 Conclusions 


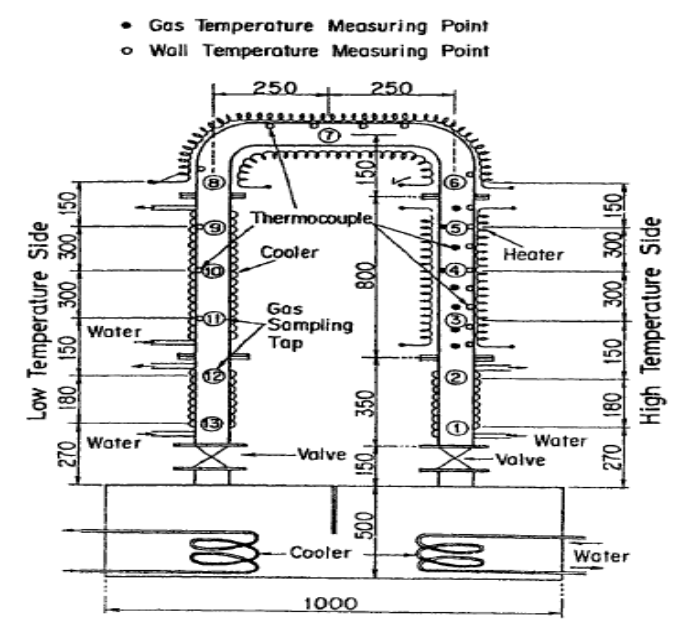

Figure 1: Hishida-Takeda air ingress experiment.

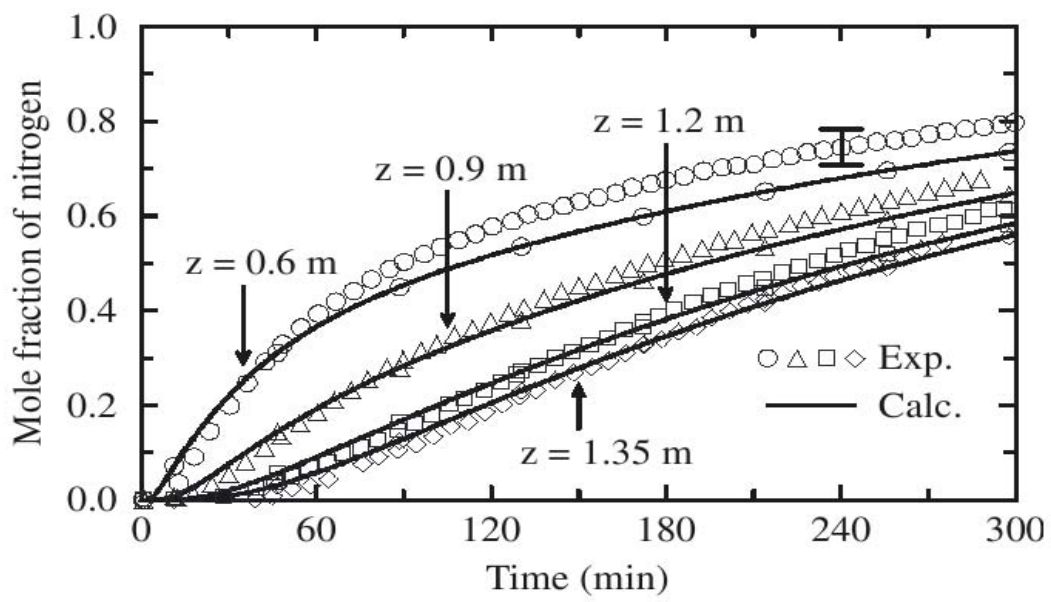

Figure 2: RELAP5-3D agreement with Hishida-Takeda experiment data.

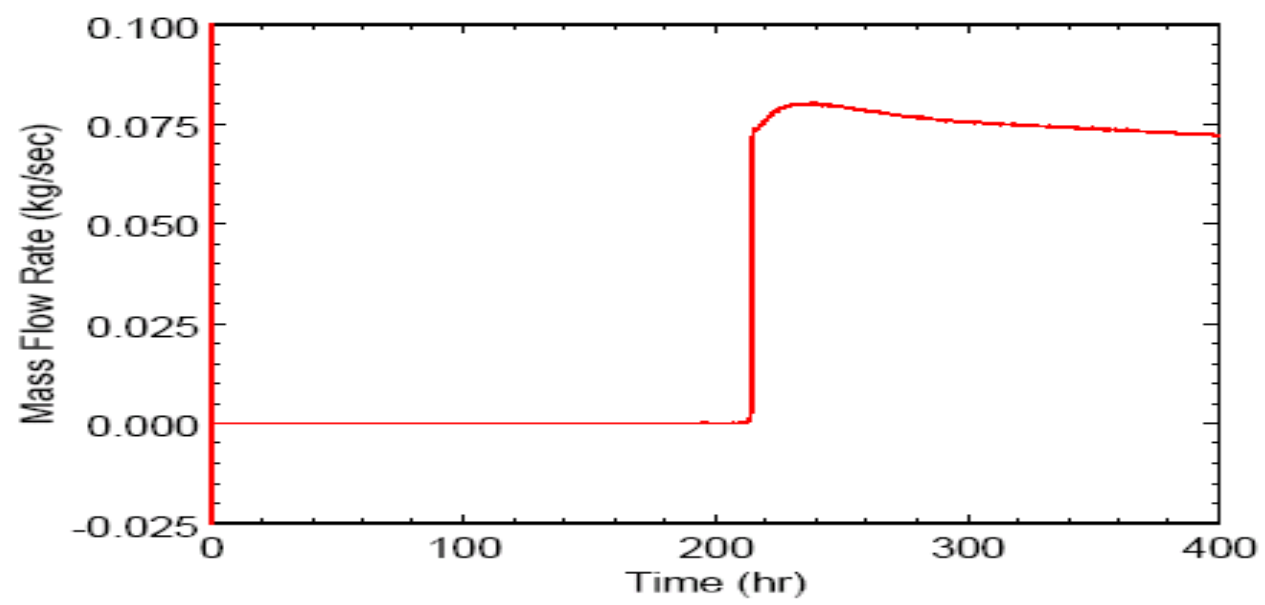

Figure 3: MELCOR-predicted VHTR mass flow rate after onset of LB-LOCA 


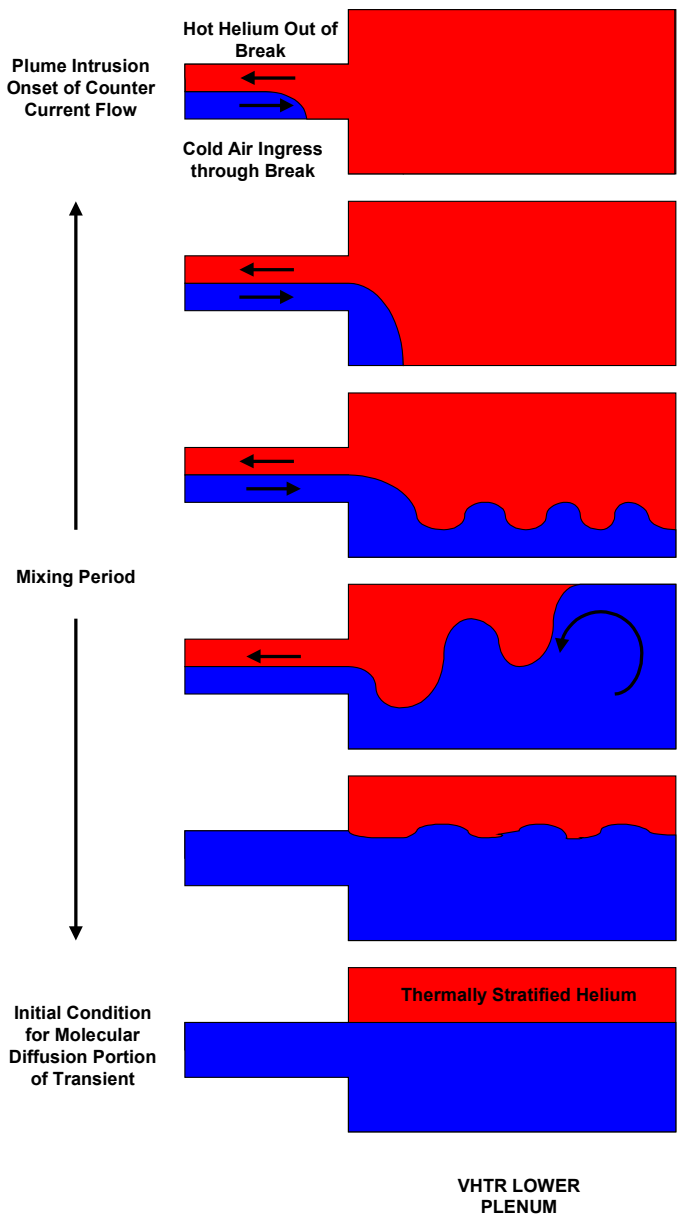

Figure 4. Conceptual snapshots of the VHTR lower plenum during the Lock-Exchange Mixing period of a Depressurized Conduction Cooldown Scenario leading up to the initial conditions for the Molecular Diffusion dominated portion of the transient. 


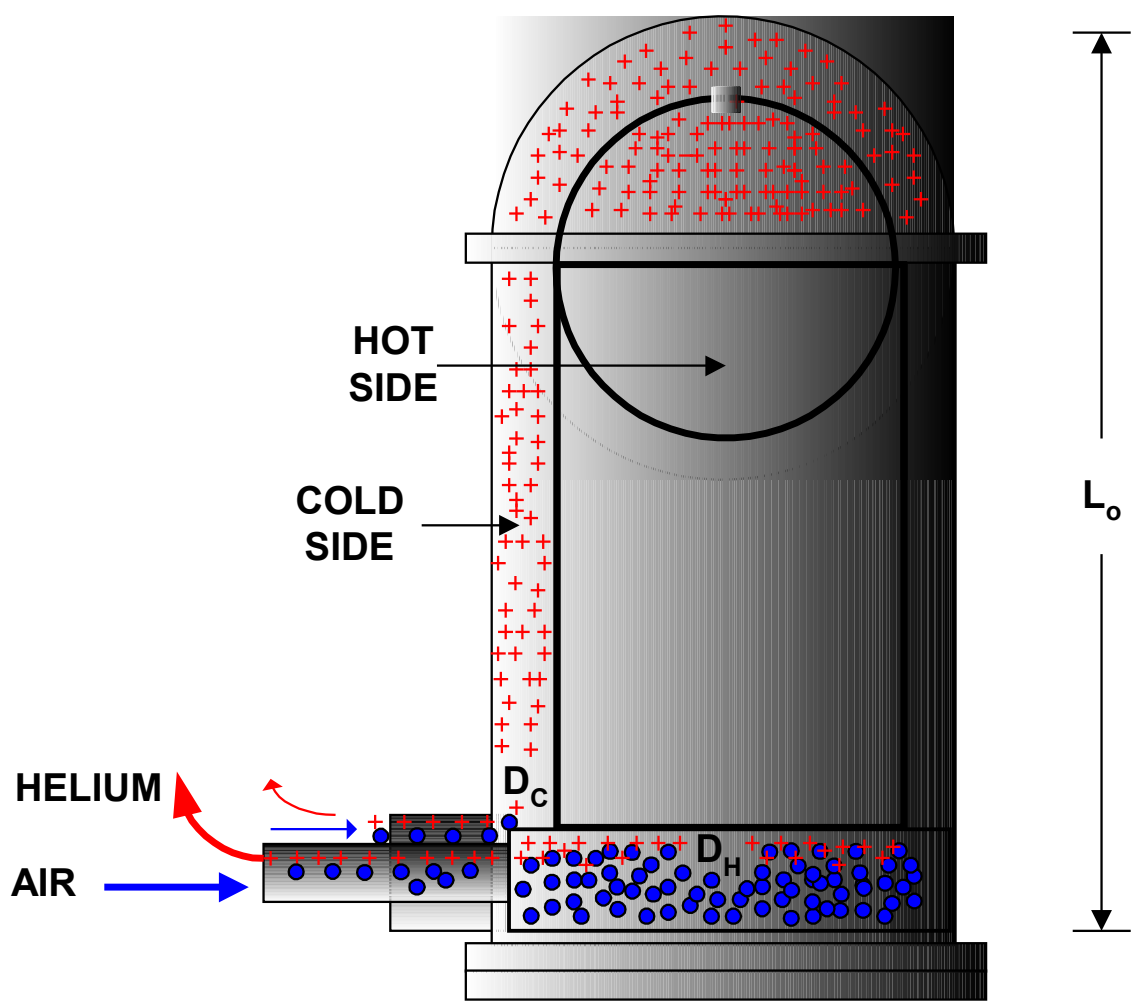

Figure 5. Air-Ingress by Molecular Diffusion on the Hot Side and Cold Side of a VHTR

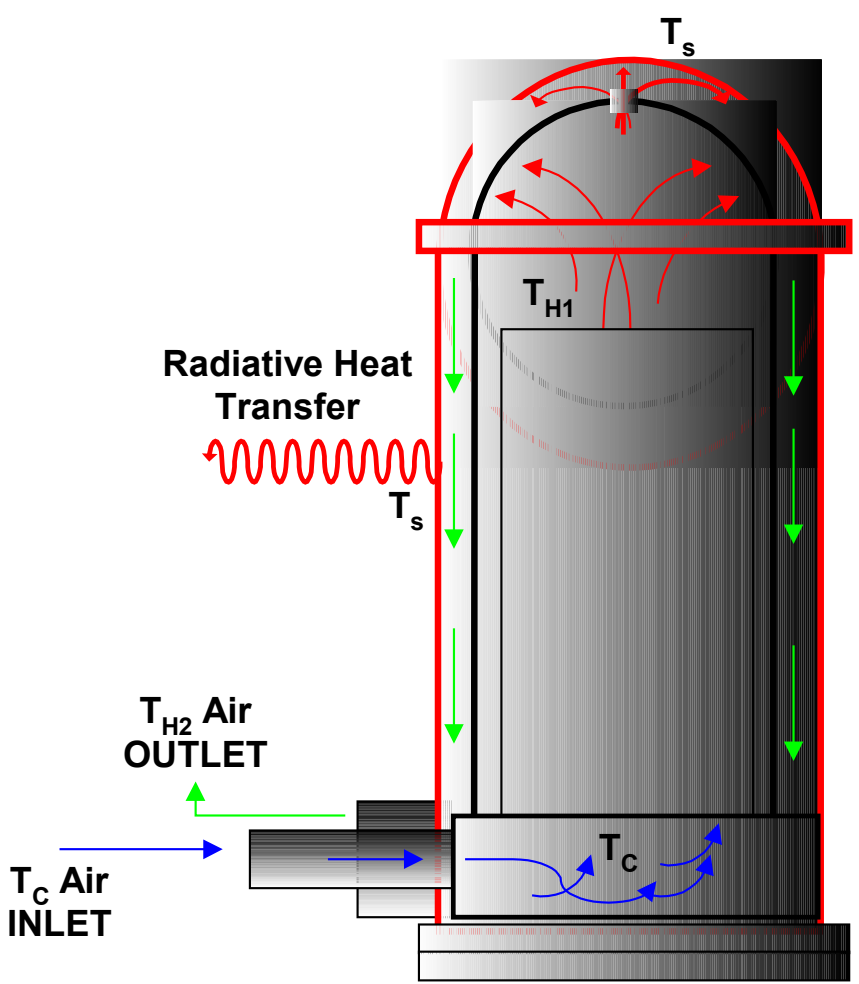

Figure 6. Hot and Cold Regions of Single-Phase Natural Circulation of Air within VHTR 
Table 1

Scale Ratios for the Design of the GRTS Model

\begin{tabular}{|l|c|}
\hline \multicolumn{1}{|c|}{ Parameter } & GRTS/VHTR Scale Ratio \\
\hline Length Scale & $1: 4$ \\
\hline Time Scale & $1: 2$ \\
\hline Velocity Scale & $1: 2$ \\
\hline Mass Flow Rate & $1: 113.7$ \\
\hline Power & $1: 113.7$ \\
\hline Flow Area & $1: 56.85$ \\
\hline Volume & $1: 227.2$ \\
\hline Helium $\Delta T$ across the Core & $1: 1$ \\
\hline Pressure Drop & $1: 4$ \\
\hline Local Area/Core Flow Area & $1: 1$ \\
\hline Loop Resistance Number & $1: 1$ \\
\hline Thermal Resistance & $113.7: 1$ \\
\hline Vessel Radiation Heat Transfer Surface Area & $1: 113.7$ \\
\hline
\end{tabular}

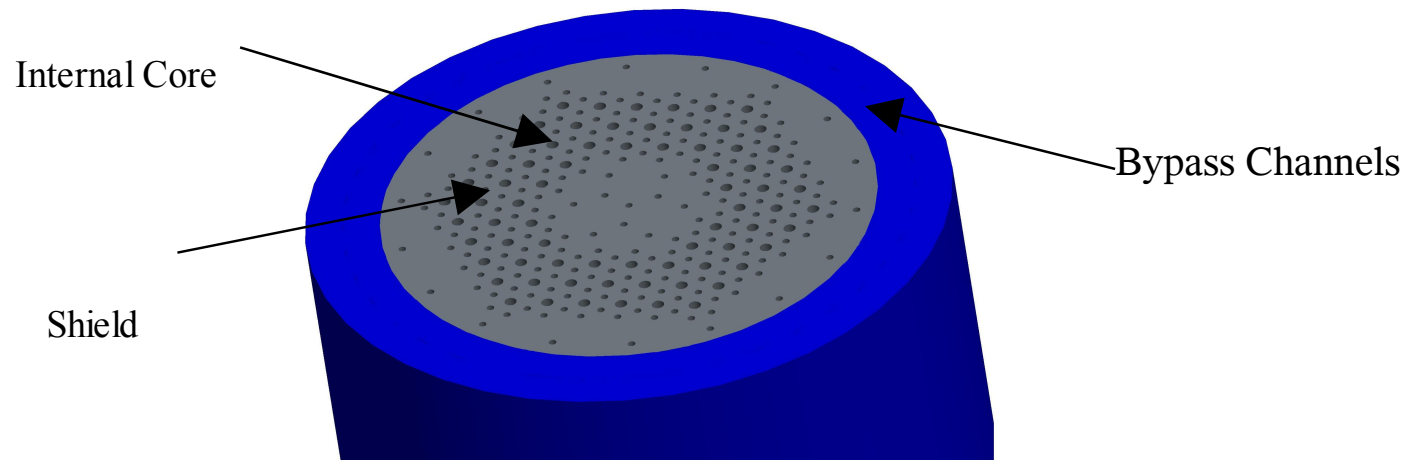

Figure 7: Inner Core with Shield 


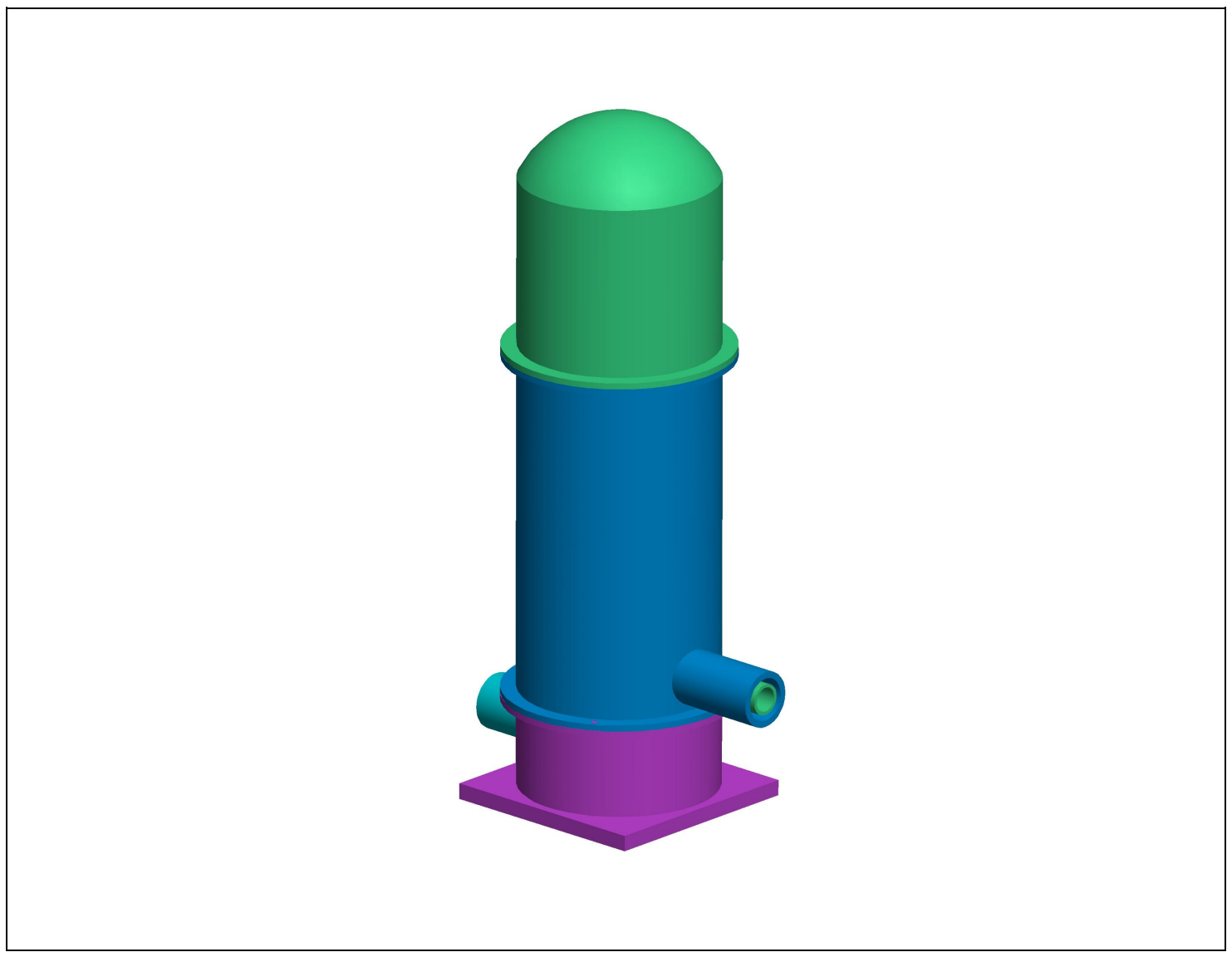

Figure 8: GRTS

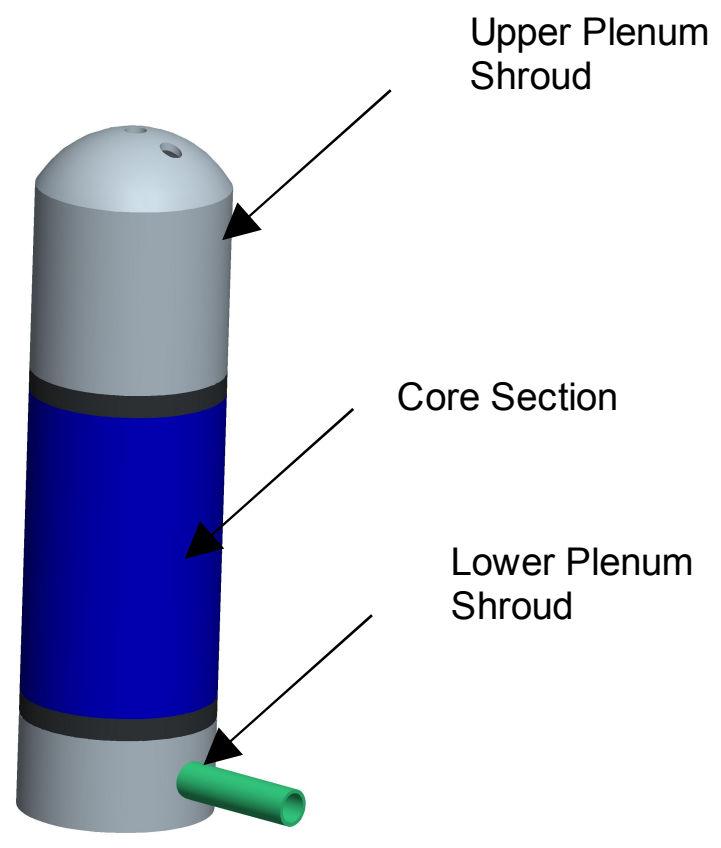

Figure 9: Inner vessel assembly 


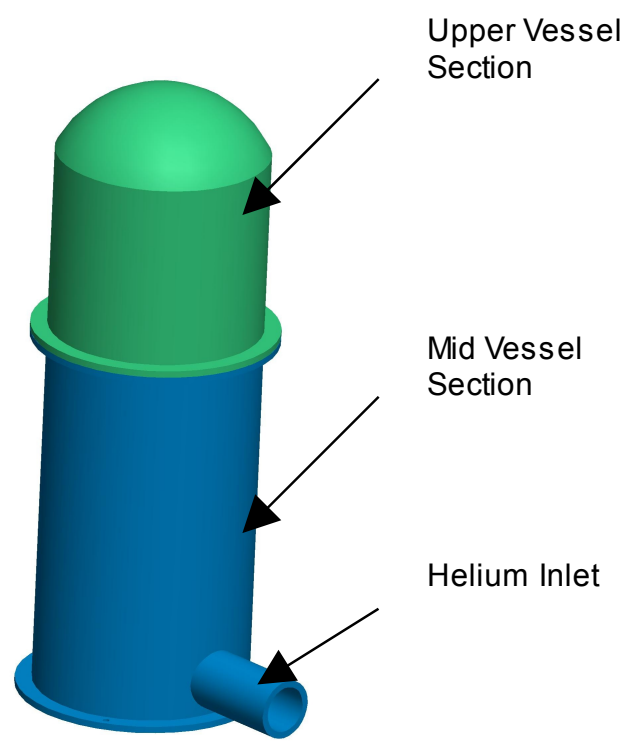

Figure 10: Outer vessel

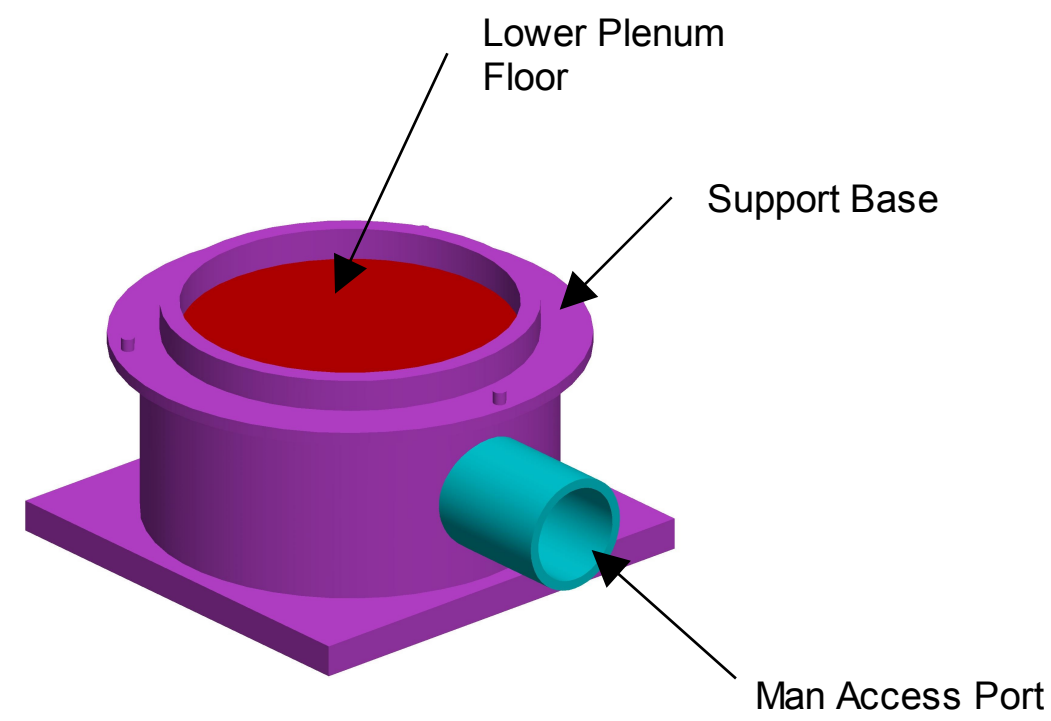

Figure 11: Base assembly 


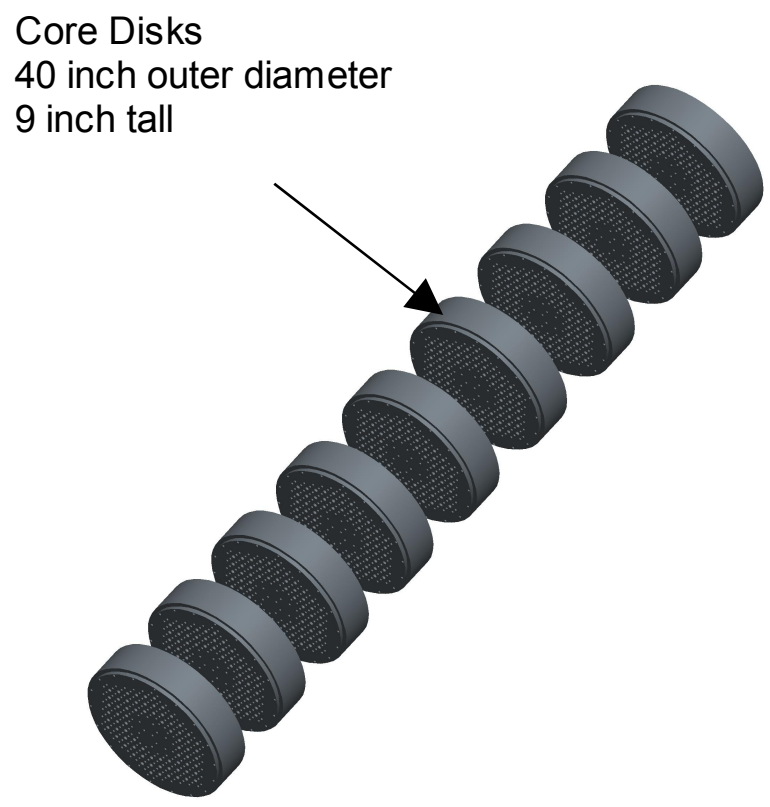

Figure 12: Core disk stacks 


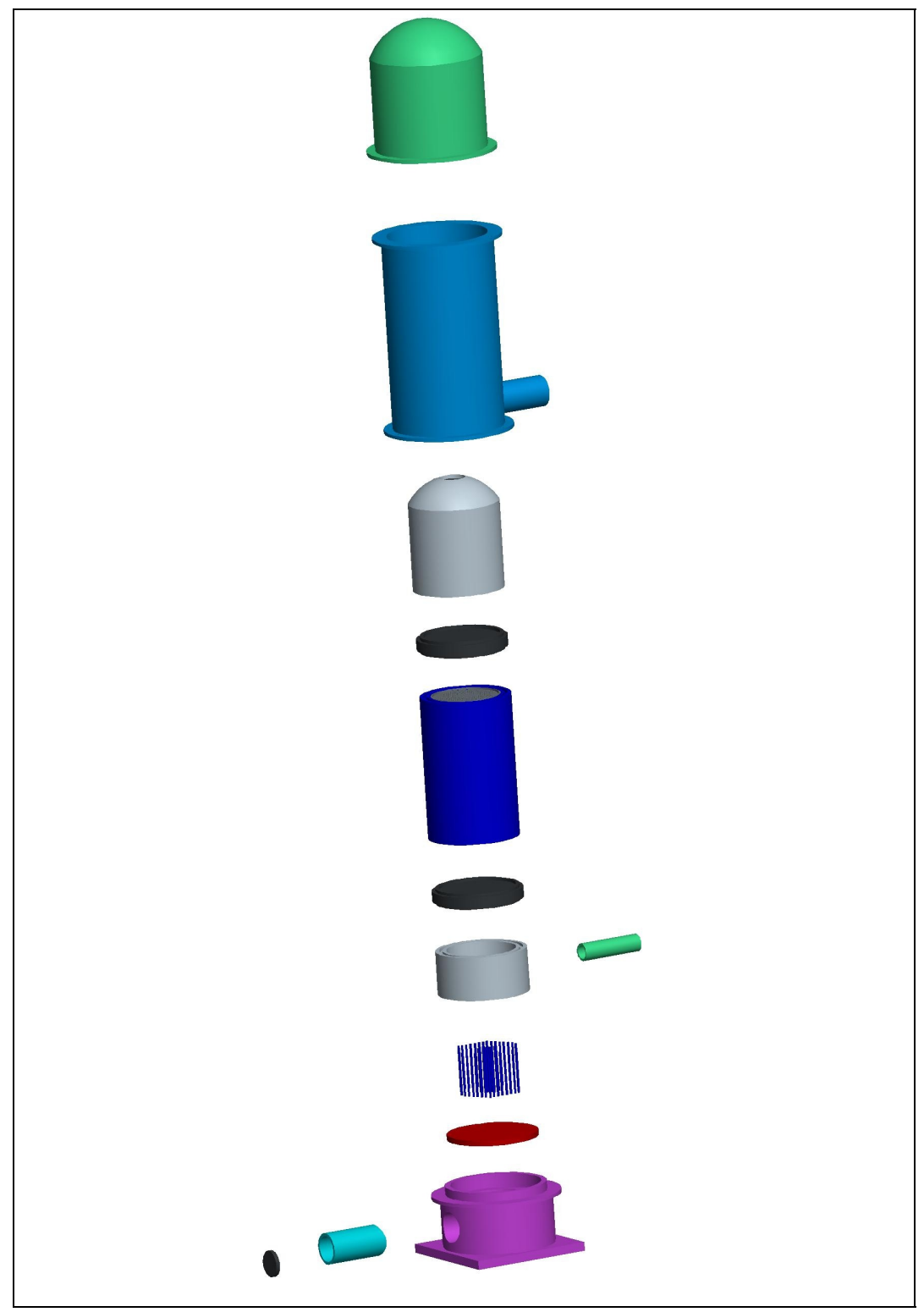

Figure 13: Exploded view of the GRTS 


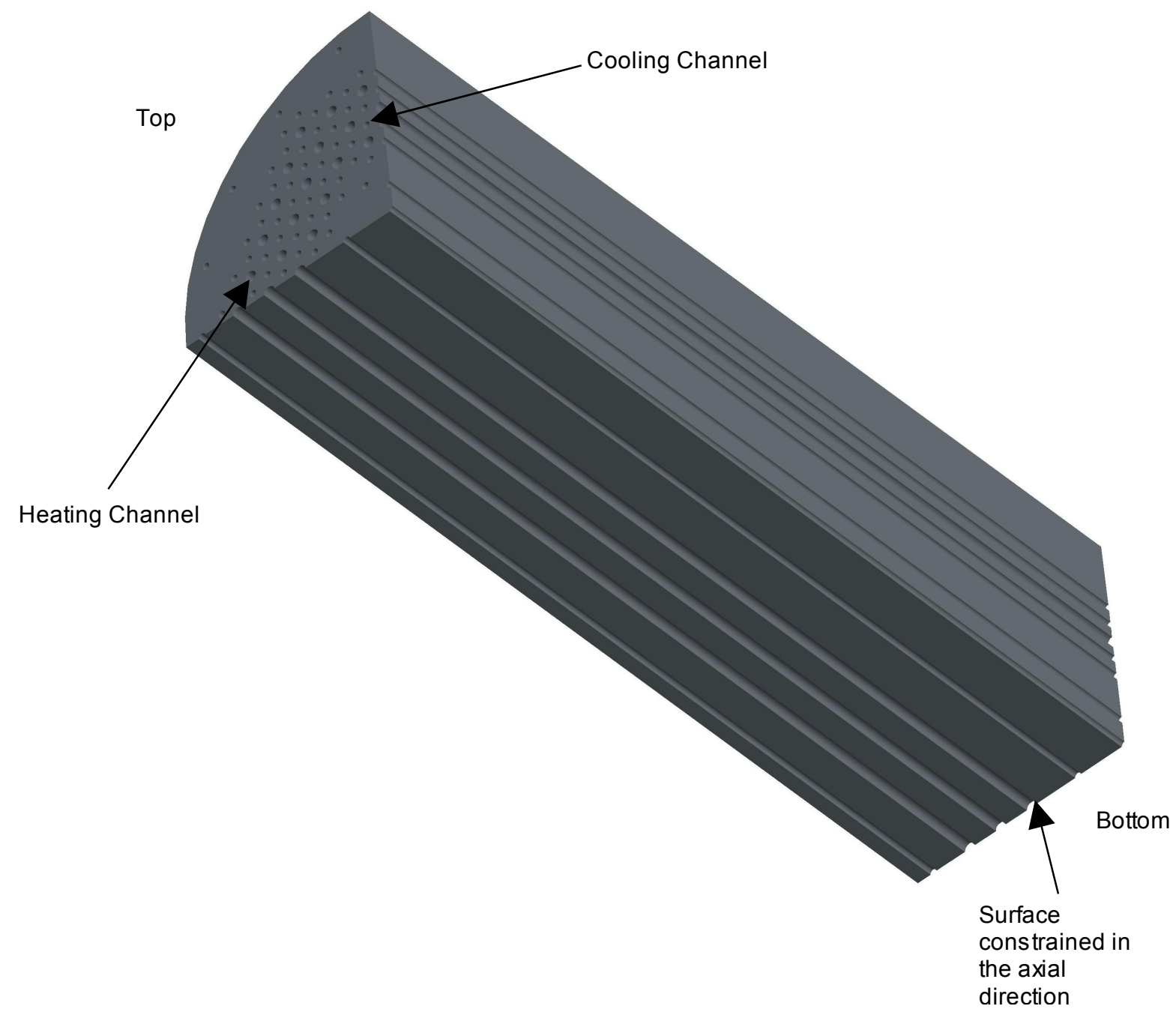

Figure 14: Finite element model 


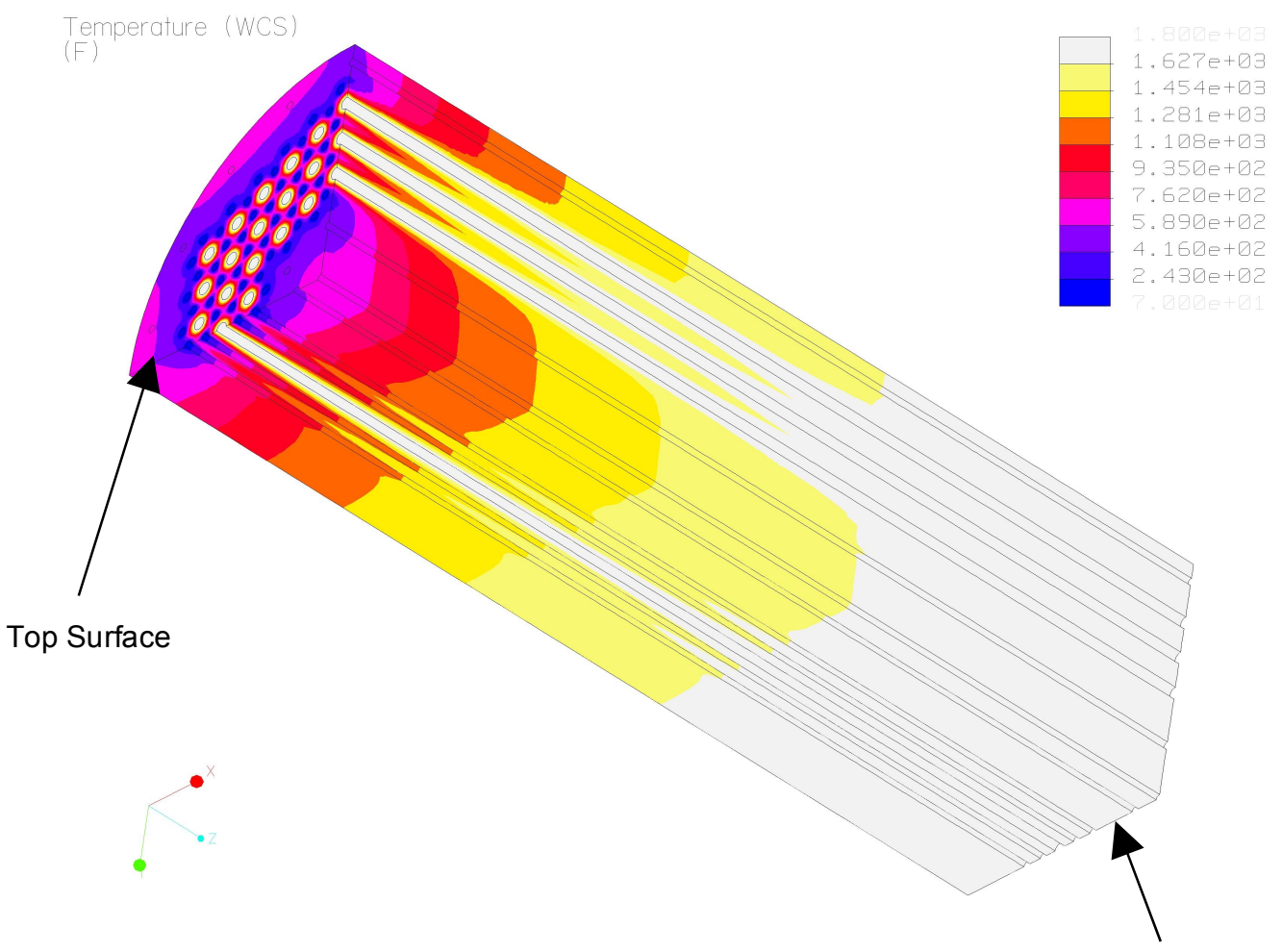

Bottom Surface

Figure 15: Axial temperature profile

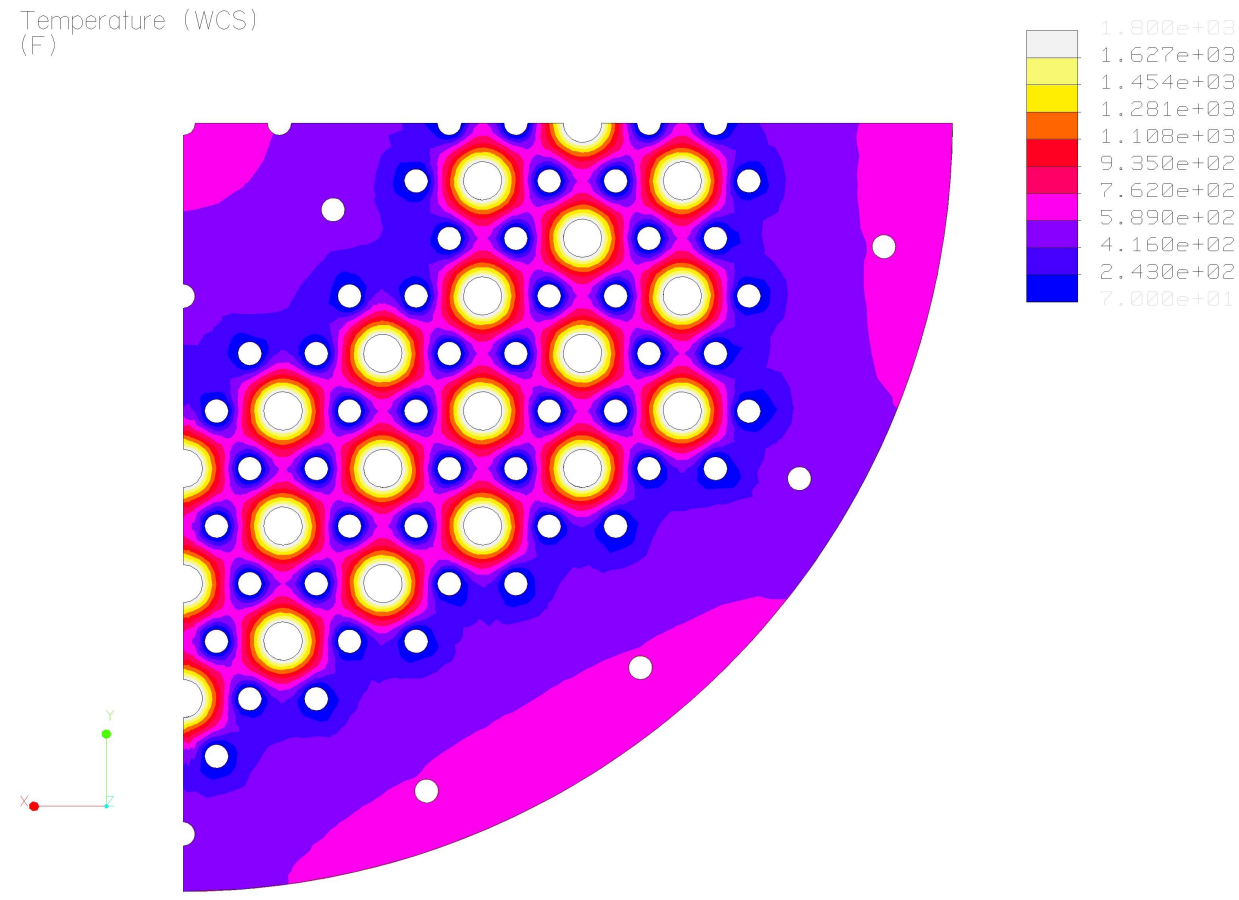

Top Surface

Figure 16: Top surface temperature profile 


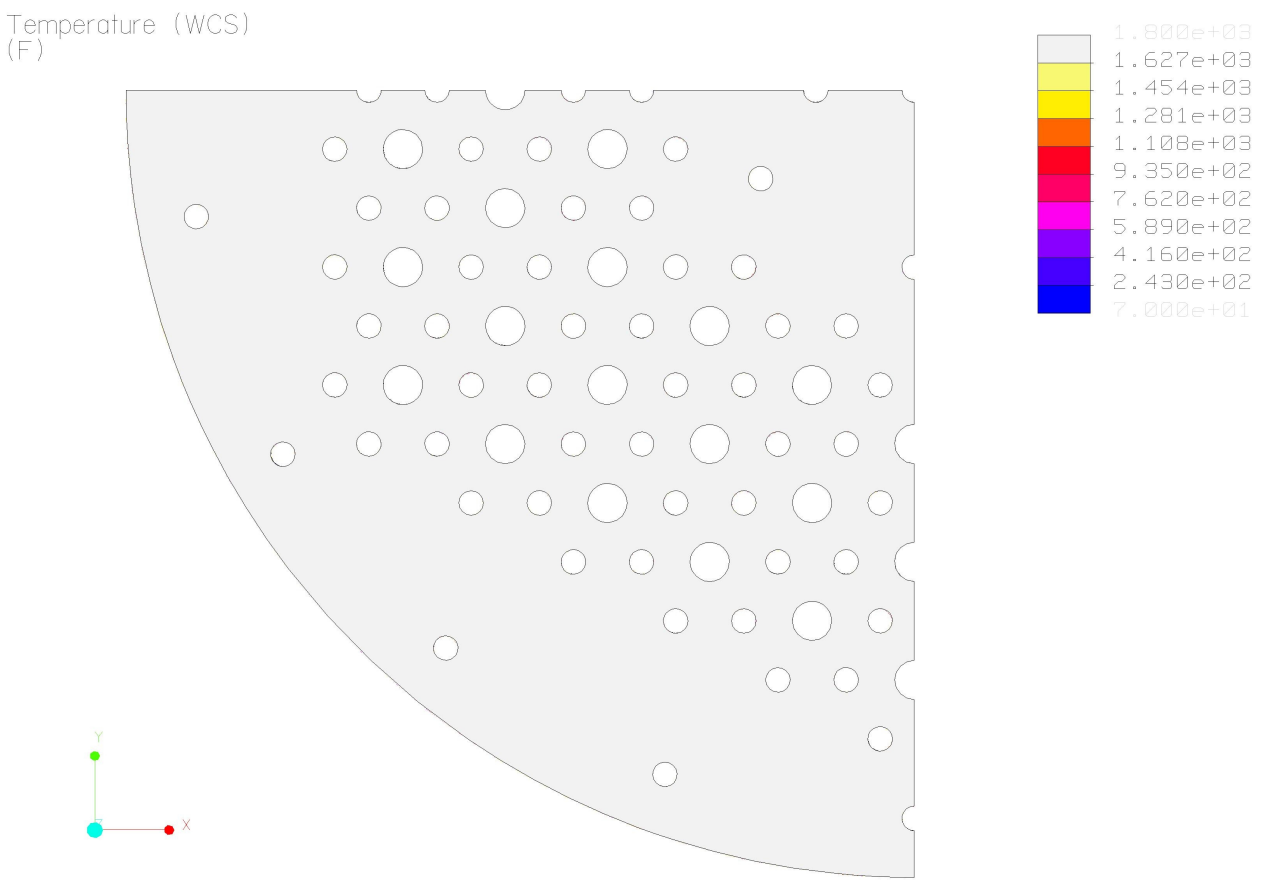

Bottom Surface

Figure 17: Bottom surface temperature profile

Table 2: Static Results

\begin{tabular}{|c|c|c|}
\hline Stress State & Max Stress (psi) & Min Stress (psi) \\
\hline Principle 1 & 120600 & -45630 \\
\hline Principle 2 & 57720 & -81600 \\
\hline Principle 3 & 29790 & -94310 \\
\hline
\end{tabular}




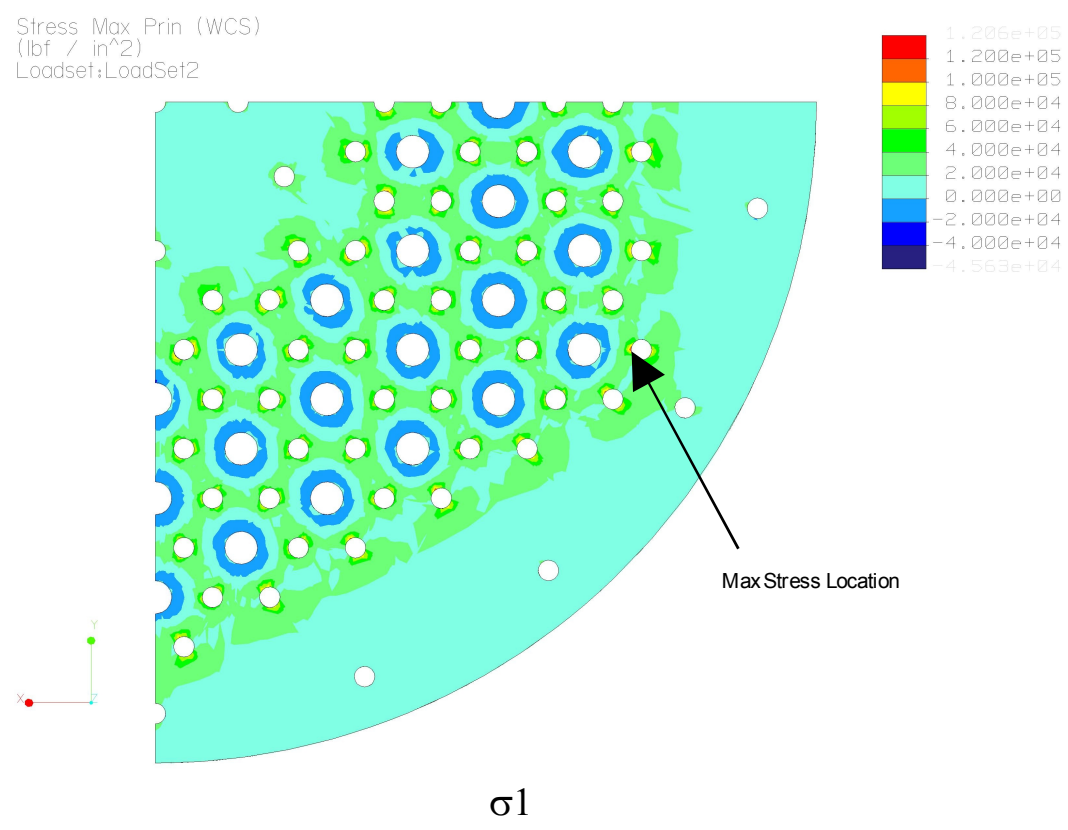

Figure 18: Principle 1 stresses

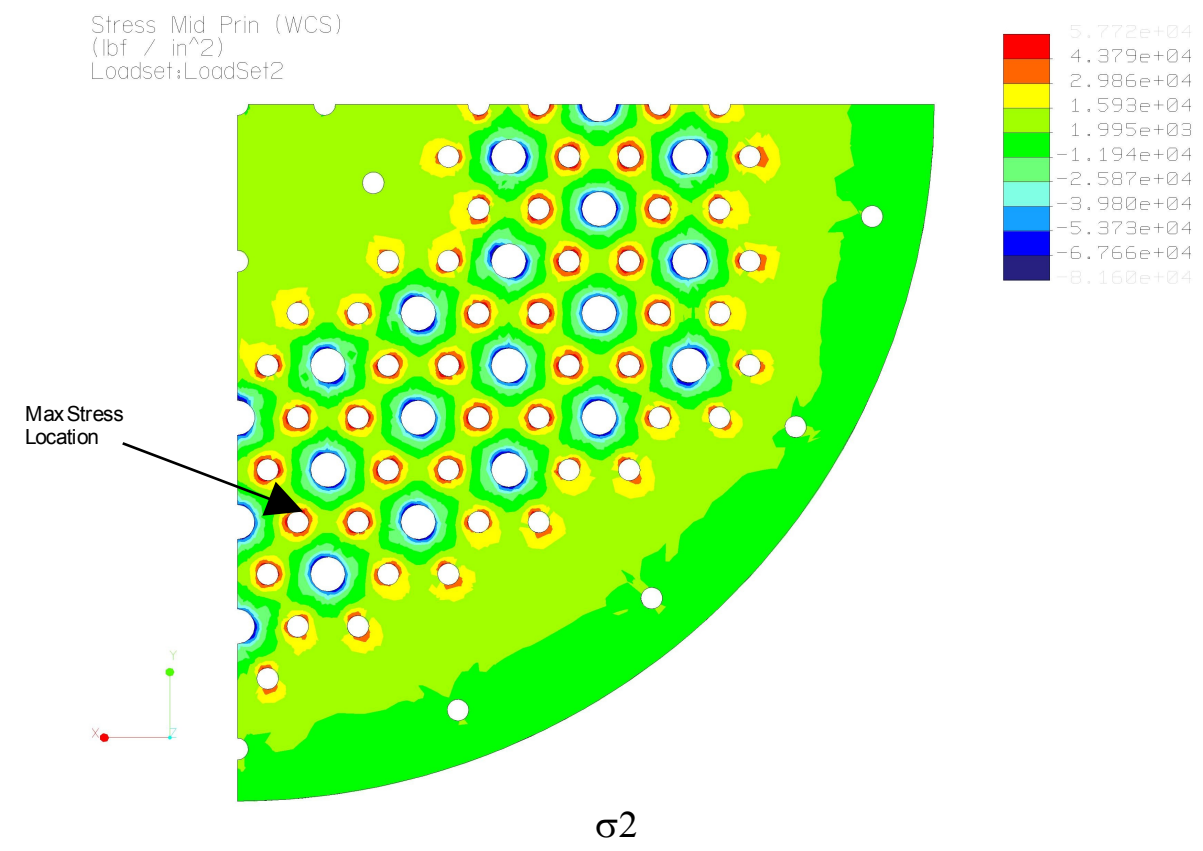

Figure 19: Principle 2 stresses 


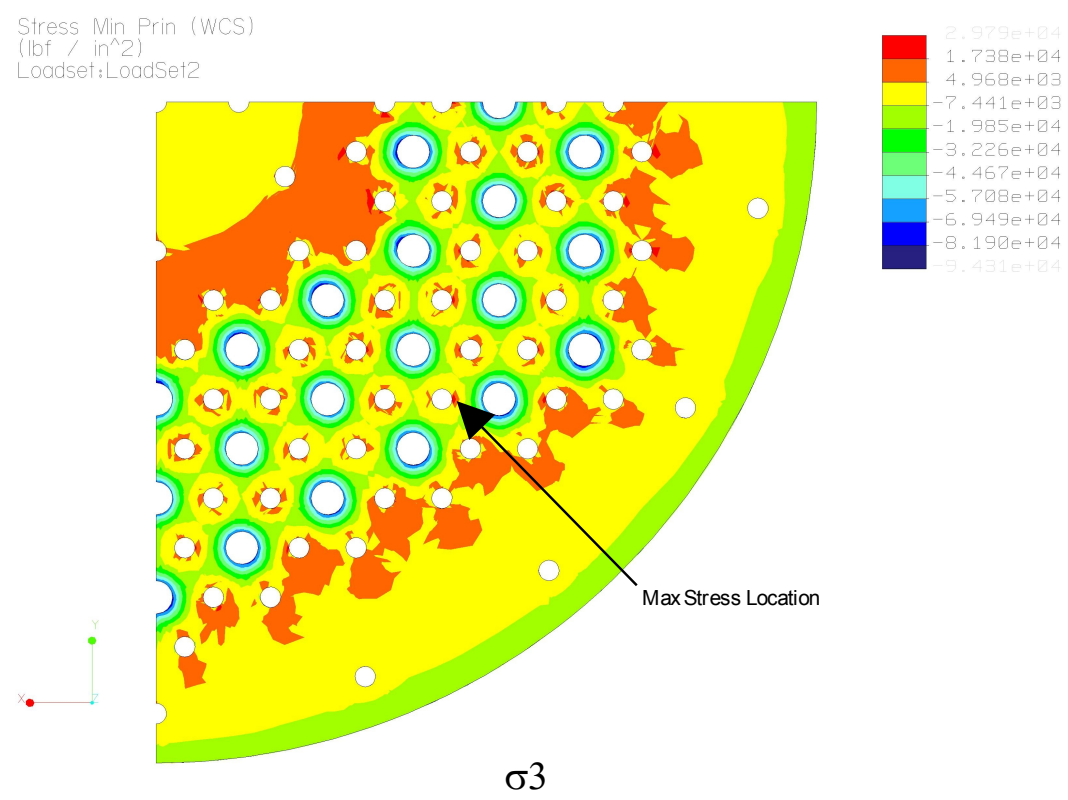

Figure 20: Principle 3 stresses

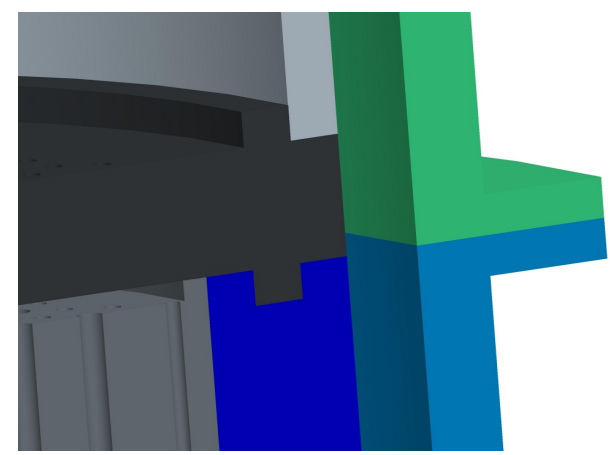

Figure 21: Illustration of flow bypass control

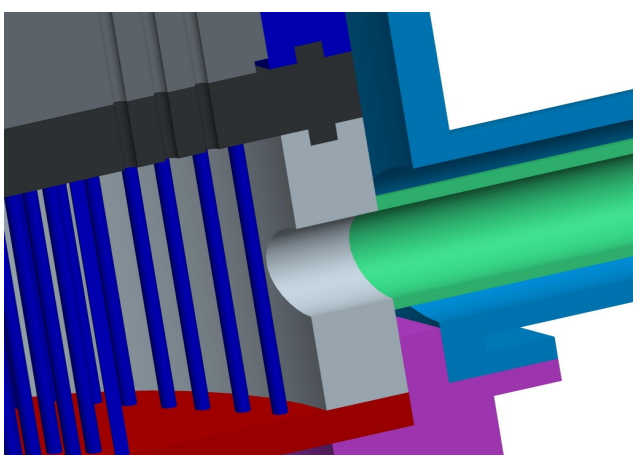

Figure 22: Location of $\mathrm{O} 2$ sensors 


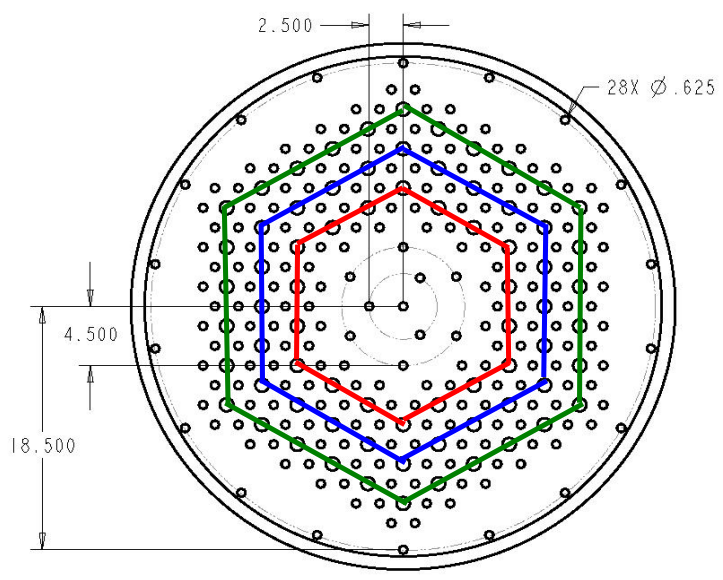

Figure 23: Radial power rings

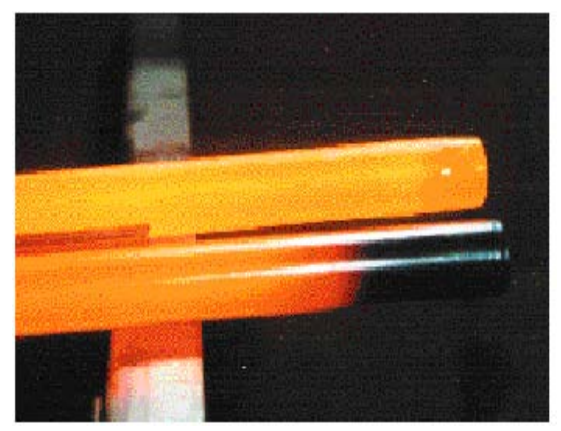

Figure 24: 3-zone cartridge heaters

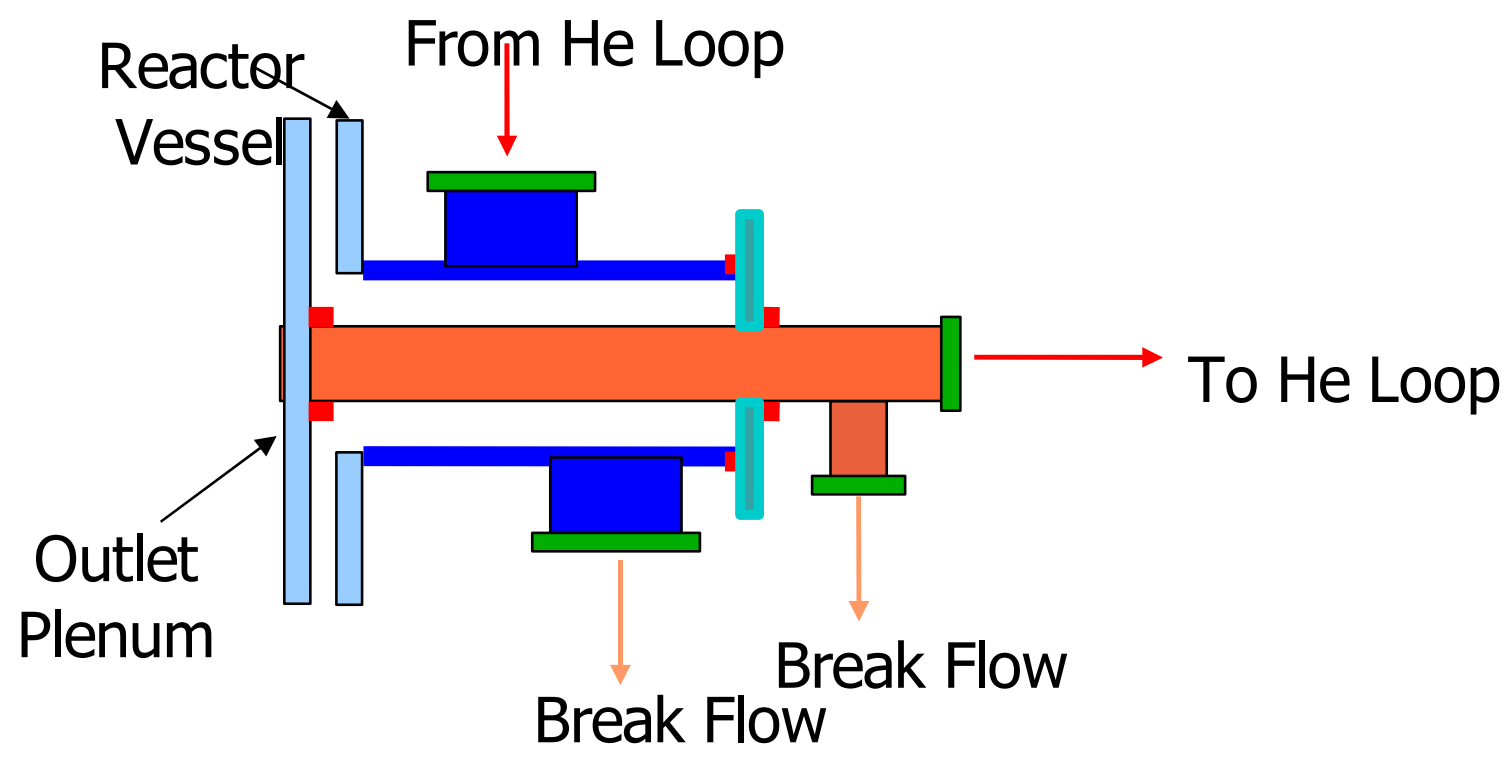

Figure 25: LB-LOCA initiation system. 